\title{
Human stem cells ameliorate auditory evoked responses in a model of neuropathy
}

Bryony Ariya Nayagam*1,2

\begin{abstract}
Stem cells have been touted as a potential source of replacement cells for the treatment of severeto-profoundly deaf individuals, including possible combined therapy with a cochlear implant. The success of such a therapy is dependent on a number of factors, but of critical importance is the functional incorporation of transplanted cells into the peripheral and central auditory systems. In a major breakthrough, Chen and colleagues recently reported the restoration of hearing thresholds by up to $46 \%$ following the transplantation of human pluripotent stem cells in a rodent auditory neuropathy model. Improved function was matched with new synapse formation in the peripheral and central aspects of the auditory system. The findings have promising clinical implications for patients with auditory neuropathy. Still to be elucidated are the long-term survival and function of transplanted cells, the precise mechanism by which hearing is restored, and whether further improvement is possible when combined with electrical stimulation from a cochlear implant.
\end{abstract}

Over the last decade, more than 40 in vivo studies have been conducted to investigate the viability of various stem cell types for the replacement of auditory neurons (ANs) in the deaf cochlea (recently reviewed in [1]). Although the majority of these studies have shown survival and differentiation of transplanted cells for various lengths of time, none has been able to demonstrate the combined integration of human stem cells into the cochlea with functional improvement in hearing thresholds. In addition, the directed differentiation of human embryonic stem cells (hESCs) toward an auditory

*Correspondence: b.nayagam@unimelb.edu.au

'Department of Otolaryngology, The University of Melbourne, Level 2, Royal Victorian Eye and Ear Hospital, 32 Gisborne Street, East Melbourne, Victoria, 3002, Australia neural lineage has been limited, and just one other study has reported differentiation of cells into auditory-like neurons expressing $\beta$ III tubulin, Brn3a, peripherin, and GATA3 [2]. The recent Nature paper by Chen and colleagues represents a major breakthrough in the field by illustrating the directed differentiation of human pluripotent stem cells into defined otic progenitors and, subsequently, into functional auditory neurosensory lineages. Impressively, the auditory-like neurons derived from these protocols improved hearing function when delivered into the denervated cochlea [3].

The directed differentiation of hESCs toward an auditory neural lineage has been challenging, owing partially to the limited knowledge of the origin of placodal progenitors during normal development. Studies have elucidated the important role of fibroblast growth factors in inner ear development [4] and the specification of the otic placode $[5,6]$, and these findings were applied by Chen and colleagues to sequentially produce otic progenitors (from three hESC lines). These otic progenitors were further differentiated under defined conditions to produce both sensory hair cell-like cells and AN-like cells which biochemically and physiologically resembled their in vivo counterparts. Although the AN-like cells expressed both $\mathrm{K}^{+}$and $\mathrm{Na}^{+}$currents, these stem cell-derived neurons were observed to fire single action potentials, which more closely resemble ANs during embryonic development [7] rather than the electrical profile of ANs in vitro [8]. While electrical activity is encouraging, these neurons presumably would need to recapitulate their in vivo physiology in order to faithfully transmit precise pitch and timing cues to the brain. This would include the expression of a specific subset of ion channels [1] and the capability to follow normal acoustic stimulation, which is in the order of 200 spikes per second for ANs [9]. Moreover, for potential future therapies combining stem cells with cochlear implantation, these stem cellderived neurons would need to be capable of following higher rates of stimulation from the implant ( $>800$ spikes per second $[9,10])$.

The transplantation of human stem cell-derived otic neural progenitors described by Chen and colleagues also represents several major advances, the combination of 
which has eluded other investigators in the field to date. These advances include the following: a significant improvement of neuronal density within Rosenthal's canal after hESC transplantation into the cochlear modiolus, expression of the afferent type I auditory neural marker NKA $\alpha 3$ in transplanted hESCs, extension of stem cell-derived processes peripherally to the hair cells (including synaptic marker expression within hESCderived fibers contacting the basal surface of the hair cells), and growth of hESC-derived processes in a central direction (with a small number of central synapses detected in the cochlear nucleus by immunochemistry). In further support of these observations, functional recovery of varying degrees was reported in all stem celltransplanted animals $(\mathrm{n}=18)$ by using auditory evoked responses. These evoked responses improved significantly from 4 until 10 weeks post-transplantation (the end-point for the study).

Although one study has reported the recovery of auditory evoked thresholds following transplantation of human-derived olfactory stem cells into the deaf cochlea [11], the transplanted cells did not integrate into the cochlear tissues and the mechanisms for repair were attributed to paracrine signaling by the cells (which remained in the perilymphatic compartments). Conversely, a different study reporting integration of hESCs into the cochlear modiolus following hearing loss [2] did not report functional improvement following transplantation. The article by Chen and colleagues combines both hESC integration and recovery of auditory evoked thresholds, and 18 transplanted animals showed significant functional improvement post-transplantation. Interestingly, the authors noted that there were considerably fewer stem cell-derived central projections growing toward the cochlear nucleus (in comparison with numbers of transplanted somata), and evidence of central synapses was detected in just three of the transplanted animals. Moreover, the authors report functional improvement across all frequencies, despite the observation that hESCs are detected only in the base of the cochlea. This suggests that further work is still required to fully elucidate the mechanism(s) by which function is restored in this model. While the detection of hESC-derived synapses in the cochlear nucleus poses several technical challenges, this difficulty will ultimately be an important aspect to investigate given the synaptic complexity and cochleotopic connectivity required for the correct transmission of sound information to the brain [12].

Future investigations should therefore examine the role of electrical stimulation in promoting the outgrowth of stem cell-derived neurons toward their central targets, which may facilitate improved synaptic and cochleotopic connectivity [1]. This idea is supported by evidence that patterned electrical stimulation delivered to the deaf mammalian cochlea can restore synapses in the cochlear nucleus [13]. In addition, the long-term survival of donor stem cells in the cochlea warrants further investigation since the side effects of chronic immunosupression can include cancer and infection [14]. This challenge may be overcome with the use of patient-matched induced pluripotent stem cells if genomic and functional instabilities can be controlled [15] along with the directed differentiation into an appropriate neural phenotype. The promising results reported by Chen and colleagues in Nature mean that we are a step closer to the clinical application of stem cells for the treatment of hearing loss from auditory neuropathy, and perhaps these findings can be extended to treat other types of hearing loss in the future.

Abbreviations

AN, auditory neuron; hESC, human embryonic stem cell.

Competing interests

The author declares that she has no competing interests.

\section{Author information}

BAN is a Senior Research Fellow in the Department of Otolaryngology of the University of Melbourne. She holds a PhD and leads the investigations relating to stem cell therapy for auditory nerve regeneration in the Department.

\section{Acknowledgments}

BAN is supported by an Australian-Based Biomedical Fellowship from the National Health and Medical Research Council of Australia. Aspects of this work have been financially supported by the University of Melbourne Department of Otolaryngology, the Royal Victorian Eye and Ear Hospital, the Bionics Institute, and project grants from the National Health and Medical Research Council of Australia and the Garnett Passe and Rodney Williams Memorial Foundation.

\section{Author details}

'Department of Otolaryngology, The University of Melbourne, Level 2, Royal Victorian Eye and Ear Hospital, 32 Gisborne Street, East Melbourne, Victoria, 3002, Australia. ${ }^{2}$ The Bionics Institute, 384-388 Albert Street, East Melbourne, Victoria, 3002, Australia.

Published: 8 November 2012

\section{References}

1. Needham K, Minter RL, Shepherd RK, Nayagam BA: Challenges for stem cells to functionally repair the damaged auditory nerve. Expert Opin Biol Ther 2012 Oct 25. [Epub ahead of print].

2. Shi F, Corrales CE, Liberman MC, Edge AS: BMP4 induction of sensory neurons from human embryonic stem cells and reinnervation of sensory epithelium. Eur J Neurosci 2007, 26:3016-3023.

3. Chen W, Jongkamonwiwat N, Abbas L, Eshtan SJ, Johnson SL, Kuhn S, Milo M, Thurlow JK, Andrews PW, Marcotti W, Moore HD, Rivolta MN: Restoration of auditory evoked responses by human ES-cell-derived otic progenitors. Nature 2012, 490:278-282.

4. Wright TJ, Hatch EP, Karabagli H, Karabagli P, Schoenwolf GC, Mansour SL: Expression of mouse fibroblast growth factor and fibroblast growth factor receptor genes during early inner ear development. Dev Dyn 2003, 228:267-272.

5. Martin K, Groves AK: Competence of cranial ectoderm to respond to Fgf signaling suggests a two-step model of otic placode induction. Development 2006, 133:877-887

6. Freter S, Muta Y, Mak SS, Rinkwitz S, Ladher RK: Progressive restriction of otic fate: the role of FGF and Wnt in resolving inner ear potential. Development 2008, 135:3415-3424

7. Marrs GS, Spirou GA: Embryonic assembly of auditory circuits: spiral ganglion and brainstem. J Physiol 2012, 590 (Pt 10):2391-2408. 
8. Mo ZL, Davis RL: Endogenous firing patterns of murine spiral ganglion neurons. J Neurophysiol 1997, 77:1294-1305.

9. Javel E, Viemeister NF: Stochastic properties of cat auditory nerve responses to electric and acoustic stimuli and application to intensity discrimination. J Acoust Soc Am 2000, 107:908-921.

10. Shepherd RK, Javel E: Electrical stimulation of the auditory nerve. I. Correlation of physiological responses with cochlear status. Hear Res 1997, 108:112-144.

11. Pandit SR, Sullivan JM, Egger V, Borecki AA, Oleskevich S: Functional effects of adult human olfactory stem cells on early-onset sensorineural hearing loss. Stem Cells 2011, 29:670-677.

12. Nayagam BA, Muniak MA, Ryugo DK: The spiral ganglion: connecting the peripheral and central auditory nervous systems. Hear Res 2011, 278:2-20.
13. Ryugo DK, Kretzmer EA, Niparko JK: Restoration of auditory nerve synapses in cats by cochlear implants. Science 2005, 310:1490-1492.

14. Marzorati S, Pileggi A, Ricordi C: Allogeneic islet transplantation. Expert Opin Biol Ther 2007, 7:1627-1645.

15. Fu X, Xu Y: Challenges to the clinical application of pluripotent stem cells: towards genomic and functional stability. Genome Med 2012, 4:55.

\section{doi:10.1186/scrt135}

Cite this article as: Nayagam BA: Human stem cells ameliorate auditory evoked responses in a model of neuropathy. Stem Cell Research \& Therapy 2012, 3:44 